\title{
CLAREAMENTO DENTAL: COM OU SEM FOTOATIVAÇÃO?
}

\section{DENTAL WHITENING: WITH OR WITHOUT PHOTOACTIVATION?}

\author{
Hugo Vinícius Cotrim Fausto* \\ Endeson Silva de Almeida * \\ Wanessa Maria de Freitas Aras **
}

\section{RESUMO}

Dentre os procedimentos estéticos, o clareamento dental é o mais conservador, pois envolve apenas o uso de substâncias clareadoras associadas ou não à aplicação de agente físico, promovendo, desse modo, mudanças cromáticas nos tecidos dentais. Entretanto, alterações pulpares e estruturais do esmalte e da dentina em dentes clareados têm sido observadas, sobretudo quando se utiliza fonte de luz ou de calor para acelerar a reação do peróxido de hidrogênio durante o clareamento. Dessa forma, o objetivo deste trabalho é revisar a literatura a respeito das vantagens e desvantagens em se realizar o clareamento com ou sem o uso de luz, abordando-se a efetividade dos agentes clareadores e os possíveis efeitos aos tecidos dentais. Para tanto, publicações científicas foram selecionadas conforme os propósitos do estudo. A partir do levantamento bibliográfico, observou-se que o clareamento dental com a utilização de fontes luminosas pode ou não trazer prejuízo intrapulpar, dependendo da intensidade e do tipo de luz utilizada.

Descritores: Clareamento dental • Peróxido de hidrogênio • Luz.

\section{ABSTRACT}

Among the cosmetic procedures, tooth whitening is the most conservative, since it involves only the use of bleaching substances associated or not to the application of physical agent, promoting thereby chromatic changes in dental tissues. However, pulp and structural changes of enamel and dentin in teeth whitened have been observed, especially when using a source of light or heat to accelerate the reaction of hydrogen peroxide during bleaching. Thus, the objective of this study is to review the literature on the advantages and disadvantages of performing bleaching with or without the use of light, addressing the effectiveness of bleaching agents and the possible effects on dental tissues. This is why scientific publications were selected according to the purposes of this study. From the literature survey, it was observed that the tooth whitening with the use of light sources may or may not bring harm intrapulpal, depending on the intensity and type of light used.

Descriptors: Tooth bleaching • Hydrogen peroxide $\bullet$ Light.

* Acadêmicos do Curso de Odontologia Universidade Estadual do Sudoeste da Bahia. E-mail: hugo fausto@hotmail.com ; endeson10@hotmail.com

** Professora Mestra do curso de Odontologia Universidade Estadual do Sudoeste da Bahia. E-mail: wanessa aras@yahoo.com.br 


\section{N T R O D U Ç Ã O}

Nos dias atuais, observa-se uma crescente preocupação do ser humano com a estética e a saúde, o que faz com que um maior número de pacientes procure o tratamento odontológico, principalmente quando se trata do aspecto da cor dos dentes. Pelos padrões de beleza propagados pela sociedade, ter um sorriso "branco" é sinônimo de status, sucesso e autoestima elevada.

As alterações na cor da estrutura dentária podem ser decorrentes de fatores extrínsecos ou intrínsecos. As manchas extrínsecas geralmente são adquiridas do meio e estão associadas a substâncias corantes presentes, por exemplo, no café e tabaco, ao acúmulo de placa e ao uso de alguns tipos de medicamento. Tais manchas são superficiais e de fácil remoção. As alterações intrínsecas, por sua vez, podem ser congênitas - relacionadas à formação dos dentes - ou adquiridas através de um trauma dental, mortificação pulpar e fluorose. Nesses casos, os pigmentos estão incorporados na estrutura dental e são removidos apenas pelo clareamento ou por procedimentos mais invasivos que implicam no desgaste e/ou restauração dos dentes ${ }^{1}$.

O clareamento dental é uma técnica não invasiva que possibilita ao cirurgião-dentista corresponder à expectativa desses pacientes, em busca de dentes mais claros e sorriso harmônico, o que estabelece um padrão de apresentação pessoal, de beleza e saúde. Além disso, e mais importante, é o fato de permitir a preservação da estrutura dental original, dispensando procedimentos restauradores invasivos para a correção das alterações de cor $^{2}$. O principal agente responsável pelo clareamento dental é o peróxido de hidrogênio, que pode ser utilizado tanto em consultório (em altas concentrações) quanto em casa (em baixas concentrações).

Conforme Nunes et al. ${ }^{3}$ (2009), é importante entender o mecanismo de ação de uma fonte luminosa na aceleração do processo clareador. As luzes utilizadas podem ser fontes de calor e, supostamente, aumentariam a temperatura do peróxido de hidrogênio. Nesse caso, o processo químico de decomposição do peróxido poderia ser catalisado. Porém, sabe-se que elevações de temperatura na estrutura dental podem causar sensibilidade dentinária severa, injúrias pulpares e danos aos tecidos moles da boca.

Buchalla e Attin ${ }^{4}$ (2007) e Marson et al..$^{5}$ (2008) afirmaram que não há diferença significativa entre as técnicas clareadoras na efetividade do agente clareador, utilizando-se ou não a fonte luminosa. Esse achado sugere que a utilização de qualquer fonte luminosa não acelera nem aumenta a eficácia do tratamento clareador. E quanto à sensibilidade dentária, ambos os estudos ${ }^{4,5}$ encontraram resposta positiva, todavia, quando se aplicou a fotoativação, esse índice foi maior. Em contrapartida, estudos atestaram que uma combinação específica entre um agente clareador e uma fonte luminosa poderia acelerar o processo clareador ${ }^{6,7}$.

Portanto, o objetivo deste trabalho foi revisar a literatura a respeito das vantagens e desvantagens em se realizar o clareamento com ou sem o uso de fonte de luz, abordando a efetividade dos agentes clareadores e os possíveis efeitos aos tecidos dentais.

\section{MÉTODOS}

O presente artigo foi desenvolvido com base em estudos científicos publicados principalmente em inglês e alguns em português nas bases de dados Scielo, Bireme e PubMed. Inicialmente, a busca foi feita utilizando-se os seguintes termos: "clareamento dental", "clareamento dental sem fotoativação", "clareamento dental com fotoativação". A pesquisa resultou em 43 artigos e, após a leitura destes, a partir do título foram selecionados 25 trabalhos. Em seguida, pela análise dos resumos, apenas 17 atenderam ao objetivo desta revisão de literatura: clareamento dental com ou sem fotoativação e seus efeitos nos tecidos dentais.

\section{REVISÃO DE LITERATURA}

O tratamento clareador vem sendo realizado há muitos anos e tem se tornado cada vez mais popular, por sua segurança, por ser uma técnica minimamente
FAUSTO HVC ALMEIDA ES ARAS WMF

CLAREAMENTO DENTAL: COM OU SEM FOTOATIVAÇÃo?

. 151

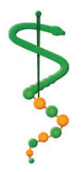

REV. ODONTOL. UNIV, CID, SÃO PAULO 2014; 26(2): $150-4$, MAIO-AGO 
FAUSTO HVC

ALMEIDA ES

ARAS WMF

CLAREAMENTO

DENTAL:

COM OU SEM

FOTOATIVAÇÃO?

$152 \ldots$

REV, ODONTOL.

UNIV, CID, SÃO

PAULO

$2014 ; 26(2):$ $150-4$, MAIO-AGO
I SSN 1983-5183

invasiva e por apresentar um custo baixo quando comparado às demais alternativas estéticas restauradoras ${ }^{8}$.

Os procedimentos realizados em consultório geralmente utilizam peróxido de hidrogênio nas concentrações de 30\% a $35 \%$, associado frequentemente a um agente físico, ou fonte de luz, para catalisar a reação de clareamento e o perborato de sódio. Os agentes clareadores caseiros ou autoadministrados pelo paciente podem ser o peróxido de hidrogênio a 1,5 ou $3,0 \%$ e o peróxido de carbamida a 10 ou $25 \%{ }^{2}$.

As pesquisas recentes estão concentradas em desenvolver agentes clareadores mais eficientes e novos sistemas que auxiliem no tratamento clareador. Muitos envolvem a combinação de agentes clareadores com novas substâncias químicas, variação na concentração, tempo de exposição aos agentes e novas fontes de ativação ${ }^{2}$. Com relação às fontes de ativação, o calor, a luz halógena ou os lasers são utilizados para aumentar a temperatura do produto clareador na superfície do dente, e tal procedimento é denominado tratamento clareador fotoativado (ou fotopotencializado), quando a luz adicional é utilizada em associação com o agente. A fonte luminosa, especificamente, ao aumentar a temperatura do gel intensifica a liberação de radicais hidroxilas a partir do peróxido, acelerando o processo clareador ${ }^{9}$. Tal reação é conhecida como termocatálise. Entretanto, se os dentes são expostos a uma fonte de luz de alta intensidade com potência maior que $1700 \mathrm{~mW} /$ $\mathrm{cm}^{2}$, poderá ocorrer sensibilidade severa que não será tolerada pelos pacientes.

Segundo Araujo et al. ${ }^{10}$ (2010), as fontes de luz melhoram a eficiência do gel branqueador na superfície dental. Por meio de estudo, constatou-se que os grupos que utilizaram peróxido de hidrogênio a 38\% associado aos LEDs azuis ou luzes halógenas tiveram os melhores desempenhos de branqueamento, com médias de 10,71 e 10,08, respectivamente. Assim, observa-se que a capacidade de ativação de luz para aumentar a eficiência do agente de branqueamento depende da fonte de luz que está sendo utilizada. Por outro lado, no grupo-controle e nos grupos tratados com lasers vermelho e verde, as médias foram inferiores e os desempenhos semeIhantes. No entanto, o potencial das fontes de luz para aumentar a eficácia de agentes de branqueamento é limitado. Ao mesmo tempo em que a luz acelera o processo, pode também produzir aquecimento. Esse aquecimento pode elevar a temperatura intrapulpar e aumentar a penetração do peróxido em direção à polpa, conduzindo ao estresse oxidativo com efeitos negativos sobre o metabolismo celular.

De acordo com Nunes et al. ${ }^{3}$ (2009), não houve diferença significativa entre os incisivos centrais submetidos ao clareamento com ou sem a utilização da fonte luminosa. Esse achado tem sido relatado por alguns trabalhos ${ }^{6,7}$, que sugerem que a utilização de qualquer fonte luminosa não acelera nem aumenta a eficácia do tratamento clareador. Por outro lado, estudos demonstraram que uma combinação específica entre um agente clareador e uma fonte luminosa poderia acelerar o processo clareador.

As fontes luminosas em altas potências têm sido estudadas no clareamento dental em consultório e são capazes de aumentar a temperatura do gel, o que pode ser desejável, porém elas também podem ser desconfortáveis para os tecidos moles e causar injúrias à polpa ${ }^{11}$.

Conforme Nunes et al. ${ }^{3}$ (2009), os lasers têm o potencial de aumentar a temperatura intrapulpar em até $5.5^{\circ} \mathrm{C}$, o que pode produzir danos irreversíveis ao tecido pulpar. Por isso, os LEDs foram introduzidos no mercado com o objetivo de aumentar a temperatura do gel sem causar danos à estrutura da polpa.

\section{I SCUSSÃO}

Há uma grande preocupação dos profissionais em saber se o clareamento fotoativado produz algum dano aos tecidos dentais, em especial à polpa. Todavia, é possível observar que a literatura consultada não responde plenamente aos questionamentos clínicos. Tal fato deve-se à publicação de poucos trabalhos sobre a temática e à falta de consenso entre os pesquisadores. Assim, verifica-se que, enquanto estudos mostram a ocorrência de efeitos adversos ao se realizar o cla- 
reamento, outros afirmam que o uso de determinada fonte de luz durante o processo clareador pode simplesmente tornar o processo mais rápido sem trazer algum dano ou efeito colateral ao paciente.

Com base nesta revisão de literatura, o uso da luz no clareamento dental apenas aumenta a velocidade de reação da substância, uma vez que se tem o mesmo efeito do gel clareador sem o seu uso, mas foi observado que, se aplicado por muito tempo ou por fontes de luz inadequadas, pode induzir a comprometimento intrapulpar ${ }^{12,13}$. Além disso, verificou-se que a sensibilidade pós-procedimento era sempre maior ${ }^{14}$. De uma forma geral, as alterações podem ocorrer levando-se em consideração alguns aspectos, tais como: tipo e concentração do agente clareador, manuseio, calor, fonte de luz. E dentre os efeitos observados destacam-se: a sensibilidade dentária, irritação da mucosa, a reabsorção radicular e a carcinogênese ${ }^{15,16}$.

Sabe-se que o clareamento deixa o dente mais poroso, por isso a sensibilidade é um fato previsível pela maior abertura dos túbulos dentinários às trocas iônicas do meio. Assim, esse aumento na abertura dos túbulos facilita a penetração do peróxido de hidrogênio em direção à polpa. Tal agente possui baixo peso molecular, por isso sua facilidade de difusão pelos tecidos dentais. Quando utilizado em altas concentrações associado ao calor eleva o risco de ocorrer reabsorções radiculares ${ }^{17}$. Na literatura, há poucos estudos que mostram efeitos carcinogênicos a partir do uso de peróxido de hidrogênio no clareamento dental em função de questões éticas e tempo de acompanhamento. No entanto, segundo Dalh e Pallesen ${ }^{15}$ (2003), não se pode excluir a ação genotóxica, pois radicais livres formados a partir de tal agente são capazes de atingir o DNA, danificando-o.
Em razão disso, cabe ao profissional que está executando o procedimento saber o mecanismo de ação da luz e utilizar fontes de luz que produzam menos calor, como é o caso da luz de LED ( Light Emitter Diode). Pois, diferentemente das outras fontes de luz, necessitam de pouca energia para a geração de luz, consequentemente produzem menos calor. Assim, diminui o risco de efeitos colaterais quando são comparados às demais fontes de luz ${ }^{8}$. Além disso, os LEDs apresentam outras vantagens, tais como custo acessível e menor utilização de energia elétrica ${ }^{1}$.

Por ser o clareamento um tratamento relativamente simples e de baixo custo em relação a outros procedimentos odontológicos, o profissional deverá estar sempre atualizado em relação aos produtos disponíveis no mercado que prometem melhores resultados, bem como adotar a associação da técnica de consultório com a técnica caseira em concentrações mais baixas, podendo-se usar por maior período de tempo e com menos efeitos colaterais.

\section{CONCLUSÃO}

Com base na revisão de literatura, conclui-se que a utilização de fontes luminosas pode ou não trazer prejuízo intrapulpar, a depender da intensidade e do tipo de luz utilizada durante o processo clareador. Assim, é mais segura a realização do branqueamento sem o uso da luz, pois traz resultados satisfatórios, evitando-se maiores danos, como o comprometimento pulpar. Em se tratando dos efeitos colaterais, estudos comprovam a relação de sensibilidade e possíveis reabsorções ao clareamento. No entanto, mais estudos devem ser realizados a fim de comparar as técnicas clareadoras com ou sem fotoativação no que se refere à ocorrência de efeitos adversos.
FAUSTO HVC

ALMEIDA ES

ARAS WMF

CLAREAMENTO

DENTAL:

COM OU SEM

FOTOATIVAÇÃO?

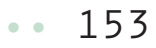

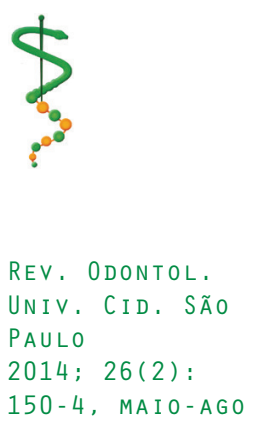


FAUSTO HVC

ALMEIDA ES

ARAS WMF

CLAREAMENTO DENTAL:

COM OU SEM FOTOATIVAÇÃO?

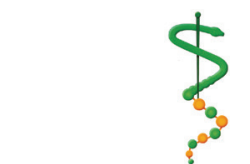

REV, ODONTOL.

UNIV. CID, SÃO

$2014 ; 26(2):$ $150-4$, MAIO-AGO

\section{REFERÊNCIAS}

1. Soares FF, Sousa JAC, Maia CC, Fontes CM, Cunha LG, Freitas AP. Clareamento em dentes vitais: uma revisão literária. Rev Saúde Com 2008 4(1):72-84.

2. Prado H, Sartori LA. Clareamento de dentes vitais amarelados. Rev Naval Odontol (Online) 2010 3(3):5-10.

3. Nunes MF, Masotti AS, Rolla JN, Soares CG, Conceição EN. Avaliação clínica do efeito de duas técnicas de clareamento dental em consultório utilizando peróxido de hidrogênio. Rev Fac Odontol Porto Alegre 2009 mai./ago.;50(2):8-11.

4. Buchalla W, Attin T. External bleaching therapy with activation by heat, light or laser--a systematic review. Dent Mater 2007 May;23(5):586-96.

5. Marson FC, Sensi LG, Vieira LC, Araujo E. Clinical evaluation of in-office dental bleaching treatments with and without the use of light-activation sources. Oper Dent 2008 Jan-Feb;33(1):15-22.

6. Luk K, Tam L, Hubert M. Effect of light energy on peroxide tooth bleaching. J Am Dent Assoc 2004 Feb;135(2):194201; quiz 28-9.

7. Tavares M, Stultz J, Newman M, Smith V, Kent R, Carpino E, et al. Light augments tooth whitening with peroxide. J Am Dent Assoc 2003 Feb;134(2):16775.

8. Haywood VB, Heymann HO. Nightguard vital bleaching. Quintessence Int 1989 Mar;20(3):173-6.

9. Moura EN, Freitas LLD, Silva NCF, Jr. MHSS, Loretto SC. Influência do clareamento dental fotoativado na resistência da união adesiva ao esmalte. Rev Odontol Bras Central 2011 20(53):140-5.
10. Araújo RM, Torres CRG, Araújo MAM. In vitro evaluation of dental bleaching effectiveness using hybrid lights activation. Rev odonto ciênc (Online) 2010 25(2):159-64.

11. Sulieman M, Addy M, Rees JS. Surface and intra-pulpal temperature rises during tooth bleaching: an in vitro study. Br Dent J 2005 Jul 9;199(1):37-40; discussion 32.

12. Baik JW, Rueggeberg FA, Liewehr FR. Effect of light-enhanced bleaching on in vitro surface and intrapulpal temperature rise. J Esthet Restor Dent 2001 13(6):370-8.

13. Klaric E, Rakic M, Sever I, Tarle Z. Temperature rise during experimental light-activated bleaching. Lasers Med Sci 2015 Feb;30(2):567-76.

14. Kossatz S, Dalanhol AP, Cunha T, Loguercio A, Reis A. Effect of light activation on tooth sensitivity after in-office bleaching. Oper Dent 2011 May-Jun;36(3):251-7.

15. Dahl JE, Pallesen U. Tooth bleaching--a critical review of the biological aspects. Crit Rev Oral Biol Med 2003 14(4):292-304.

16. Tredwin CJ, Naik S, Lewis NJ, Scully C. Hydrogen peroxide tooth-whitening (bleaching) products: review of adverse effects and safety issues. Br Dent J 2006 Apr 8;200(7):371-6.

17. Friedman S, Rotstein I, Libfeld H, Stabholz A, Heling I. Incidence of external root resorption and esthetic results in 58 bleached pulpless teeth. Endod Dent Traumatol 1988 Feb;4(1):23-6.

Recebido em 25/11/2013

Aceito em 02/02/2014 